\title{
Anti-Helicobacter pylori activity in vitro of chamomile flowers, coneflower herbs, peppermint leaves and thyme herbs - a preliminary report
}

\author{
Anna Malm $^{1 *}$, Anna Glowniak-Lipa ${ }^{1}$, Izabela Korona-Glowniak ${ }^{1}$, Tomasz Baj ${ }^{2}$ \\ ${ }^{1}$ Department of Pharmaceutical Microbiology with Laboratory for Microbiological Diagnostics, Medical University of Lublin, \\ 1 Chodzki, 20-093 Lublin, Poland \\ ${ }^{2}$ Department of Pharmacognosy with Medicinal Plant Unit, Medical University of Lublin, 1 Chodzki, 20-093 Lublin, Poland
}

\begin{tabular}{l}
\hline ARTICLE INFO \\
\hline Received 02 March 2015 \\
Accepted 17 March 2015 \\
\hline
\end{tabular}

Keywords: anti-Helicobacter pylori activity, chamomile flowers, coneflower herbs, peppermint leaves, thyme herbs.

\begin{abstract}
Recently, several studies have been undertaken so as to develop more effective therapeutic approaches towards eradicating Helicobacter pylori. Among these is phytotherapy. The aim of this study was to investigate the activity in vitro of the plant extracts obtained from common herbs cultivated in the Lubelszczyzna region against the reference strain H. pylori ATCC 43504. Among these are thyme herbs, chamomile flowers, peppermint leaves and coneflower herbs. Herein, it was found that the MIC values of the assayed extracts were as follows: the extracts from coneflower herbs showed anti- $H$. pylori activity with MIC = $31.3-125 \mu \mathrm{g} / \mathrm{ml}$; the extracts from chamomile flowers demonstrated MIC $=31.3-62.5 \mu \mathrm{g} /$ $\mathrm{ml}$; the extracts from peppermint leaves had MIC $=15.6-250 \mu \mathrm{g} / \mathrm{ml}$; and the extracts from thyme herbs revealed MIC $=15.6-62.5 \mu \mathrm{g} / \mathrm{ml}$, depending on the solvent used. The most active were the extracts obtained with ethyl acetate or ethanol alcohol absolute $99.8 \%$. These showing MIC within the range of $15.6-62.5 \mu \mathrm{g} / \mathrm{ml}$, while the lowest activity was observed in case of the extract obtained with $70 \%$ aqueous ethanol. This last showing MIC within the range of $62.5-250 \mu \mathrm{g} / \mathrm{ml}$. The MIC values of essential oil components were $15.6 \mu \mathrm{g} / \mathrm{ml}$ for bisabolol and menthol or $31.3 \mu \mathrm{g} / \mathrm{ml}$ for thymol. The obtained data indicate that the assayed herbs possessed promising anti-H. pylori bioactivity.
\end{abstract}

\section{INTRODUCTION}

Helicobacter pylori is one of the most common bacterial species worldwide. This bacterial species has colonized the human stomach, with a high prevalence $(>50 \%)$ in much of the world, although the infection rates are dropping in some developed countries, reaching $<25 \%$. H. pylori is an important cause of gastritis, peptic ulcer disease, gastric mucosaassociated lymphoid tissue lymphoma, and gastric adenocarcinoma [12]. The effectiveness of standard triple therapy for the eradication of $H$. pylori has decreased recently due to its increasing resistance to antibacterials, mostly clarithromycin, with failure rate of up to $40 \%$. Therefore, further studies are performed so as to develop more effective therapeutic approaches, including alternative therapeutic approaches, e.g. phytomedicine [12]. However, the available in vitro

\footnotetext{
* Corresponding author

e-mail: anna.malm@umlub.pl

tel./fax: +48 81 448-71-00, +48 81 448-71-02
}

data on the activity of plant extracts or essential oils against H. pylori and data from clinical trials concerning the use of herbal medicines for treating $H$. pylori infection are controversial and not complete $[14,16,17]$. The aim of this study was to investigate the activity of the plant extracts obtained from common herbs cultivated in the Lubelszczyzna region (chamomile flowers, coneflower herbs, peppermint leaves and thyme herbs) against $H$. pylori.

\section{MATERIAL AND METHODS}

Extraction procedure. Plant material for the study were: chamomile flowers (Matricaria chamomilla L., Asteraceae), coneflower herbs (Echinacea purpurea (L.) Moench., Asteraceae), peppermint leaves (Mentha piperita L., Lamiaceae) and thyme herbs (Thymus vulgaris L., Lamiaceae); this material was purchased from the herbal Trading Company KRAUTEX, Lopiennik Gorny, Poland. The dry 
material was first milled and sieved. The dry plants' medicinal components were then extracted by way of different solvents: ethanol alcohol absolute 99,8\% (POCh, Gliwice, Poland), ethanol 96\% (pure-basic, POCh Gliwice, Poland), $70 \%$ aqueous ethanol or ethyl acetate (ACS pure p.o., POCh Gliwice, Poland), at room temperature (about $25^{\circ} \mathrm{C}$ ), by using the maceration method, for $48 \mathrm{~h}$, in a 1:10 material/ solvent ratio. After extraction, the samples were filtered using standard filter paper. The solvents were subsequently evaporated by way of employing the rotary evaporator (IKA RV Basic, Germany) under reduced temperature below $50^{\circ} \mathrm{C}$. The amorphous solid crude extracts were then tested for microbial properties. In the case of that treated by way of $70 \%$ aqueous ethanol solvent, samples were evaporated under reduced pressure, and the obtained residue was frozen in a vertical low temperature freezer (GLF, Germany) at $-50^{\circ} \mathrm{C}$ and then lyophilized (Christ, Alpha 2-4 LD Plus, Germany).

Antibacterial activity assay in vitro. The extracts obtained from coneflower herbs, chamomile flowers, peppermint leaves and thyme herbs were screened for activity towards H. pylori ATCC 43504 (the reference strain being obtained from the American Type Culture Collection), by way of the micro-dilution broth method, using Mueller-Hinton broth supplemented with lysed horse blood, allowing for the determination of the minimal inhibitory concentration (MIC) of the tested extracts. Serial two-fold dilutions were made in order to obtain final concentrations of the tested extracts, which ranged from 0.98 to $1000 \mu \mathrm{g} / \mathrm{mL}$. The sterile 96-well polystyrene microtitrate plates (Nunc, Denmark) were prepared by dispensing $200 \mu 1$ of appropriate dilution of the tested extract in broth medium per well. The inocula were prepared with fresh microbial cultures in sterile $0.85 \%$ $\mathrm{NaCl}$ to match the turbidity of $1.0 \mathrm{McFarland}$ standard, and $2 \mu \mathrm{l}$ were added to the wells to obtain a final density of $3.0 \times$ $10^{6} \mathrm{CFU}$ (colony forming units) $/ \mathrm{ml}$. After incubation at $35^{\circ} \mathrm{C}$ for $72 \mathrm{~h}$ under microaerophilic conditions $\left(5 \% \mathrm{O}_{2}, 15 \% \mathrm{CO}_{2}\right.$ and $80 \% \mathrm{~N}_{2}$ ), the MICs were assessed visually as the lowest concentration of the extracts showing complete growth inhibition of the reference strain. A positive control (containing inoculum without the tested extracts) and a negative control (containing the tested extracts without inoculum) were included on each microplate. Bisabolol alpha, menthol, and thymol (P.P.H. "Standard", Poland) were used as the reference substances. Minimal bactericidal concentration (MBC) was determined by subculturing $100 \mu$ l of the microbial culture from each well that showed thorough growth inhibition, from the last positive and from the growth control, onto the plates of Mueller-Hinton agar supplemented with horse blood. The plates were incubated at $35^{\circ}$ for $72 \mathrm{~h}$ under microaerophilic conditions, and the $\mathrm{MBC}$ was defined as the lowest concentration of the extracts without growth of microorganisms. The $\mathrm{MBC} / \mathrm{MIC}$ ratios were calculated to determine the bactericidal or bacteriostatic effect of the assayed extracts. Of note, in our work, antibacterial agents are usually regarded as bactericidal if $\mathrm{MBC} / \mathrm{MIC}$ is no more than four times the MIC [6]. Each experiment was repeated in triplicate. Representative data are presented.

\section{RESULTS}

The activity of the extracts from coneflower herbs, chamomile flowers, peppermint leaves and thyme herbs towards H. pylori ATCC 43504 was determined in vitro by way of employing the micro-dilution broth method, allowing for the determination of MIC. The extracts were obtained using solvents of different polarity. The obtained data are shown in Table 1. As seen in the table, the MIC values of the assayed plant extracts ranged from 15.6-250 $\mu \mathrm{g} / \mathrm{ml}$, depending on the plant material and solvent. The extracts from chamomile flowers showed activity against the reference strain of $H$. pylori with MIC $=31.3-62.5 \mu \mathrm{g} / \mathrm{ml}$, while the extracts from coneflower herbs showed MIC $=31.3-125 \mu \mathrm{g} / \mathrm{ml}$, the extracts from peppermint leaves had $\mathrm{MIC}=15.6-250$ $\mu \mathrm{g} / \mathrm{ml}$, and the extracts from thyme herbs revealed $\mathrm{MIC}=$ 15.6-62.5 $\mu \mathrm{g} / \mathrm{ml}$. The most active were the plant extracts obtained either with ethyl acetate or ethanol (99.8\%), both showing MIC within the range of 15.6-62.5 $\mu \mathrm{g} / \mathrm{ml}$, while the lowest activity was observed in case of the extract obtained by way of ethanol $(70 \%)$ - this showing MIC within the range of $62.5-250 \mu \mathrm{g} / \mathrm{ml}$. Furthermore, the MIC values of essential oil components were $15.6 \mu \mathrm{g} / \mathrm{ml}$ for bisabolol and menthol or $31.3 \mu \mathrm{g} / \mathrm{ml}$ for thymol.

Table 1. The antimicrobial activity of the tested plant extracts towards Helicobacter pylori ATCC43504

\begin{tabular}{|l|c|c|c|c|}
\hline Extract (solvent) & Plant material & $\begin{array}{c}\mathrm{MIC} \\
(\mu \mathrm{g} / \mathrm{ml})\end{array}$ & $\begin{array}{c}\mathrm{MBC} \\
(\mu \mathrm{g} / \mathrm{ml})\end{array}$ & $\begin{array}{c}\mathrm{MBC} / \mathrm{MIC} \\
\text { ratio }\end{array}$ \\
\hline Extract no 1 & coneflower herbs & 62.5 & 125 & 2 \\
(ethyl acetate) & chamomile flowers & 31.3 & 125 & 4 \\
& peppermint leaves & 15.6 & 125 & 8 \\
& thyme herbs & 15.6 & 125 & 8 \\
\hline & coneflower herbs & 31.3 & 62.5 & 2 \\
Extract no 2 & chamomile flowers & 62.5 & 125 & 2 \\
(ethanol 99.8\%) & peppermint leaves & 15.6 & 125 & 8 \\
& thyme herbs & 31.3 & 250 & 8 \\
\hline & coneflower herbs & 62.5 & 250 & 4 \\
Extract no 3 & chamomile flowers & 62.5 & 250 & 4 \\
(ethanol 96\%) & peppermint leaves & 62.5 & 250 & 4 \\
& thyme herbs & 31.3 & 250 & 8 \\
\hline & coneflower herbs & 125 & 125 & 1 \\
Extract no 4 & chamomile flowers & 62.5 & 250 & 4 \\
(ethanol 70\%) & peppermint leaves & 250 & 250 & 1 \\
& thyme herbs & 62.5 & 125 & 2 \\
\hline \multirow{2}{*}{ Essential oil } & bisabolol & 15.6 & 31.3 & 2 \\
constituents & menthol & 15.6 & 62.5 & 4 \\
& thymol & 31.3 & 62.5 & 2 \\
\hline
\end{tabular}

As presented in Table 1, the MBC/MIC values of the plant extracts $\leq 4$ suggested their bactericidal activity against H. pylori ATCC 43504, while the MBC/MIC values of the extracts $>4$ demonstrated their bacteriostatic activity. By way of reference, the essential oil components studied, i.e. bisabolol, menthol and thymol, showed bactericidal activity against the reference strain of $H$. pylori, with $\mathrm{MBC} /$ MIC values $\leq 4$.

\section{DISCUSSION}

Numerous plant species have been utilized as traditional medicine (phytotherapy) in many parts of the world, for thousands of years. The employed medicinal plants contain a lot of biologically active compounds, e.g. essential oils, and may display potential antimicrobial properties $[2,3,8,13]$. Indeed, phytotherapy has been used for centuries to treat various gastrointestinal tract disorders. The gastroprotective effects of herbs are multidirectional, including anti-H. pylori 
activity. Herbs with potent anti-H. pylori effects were found to belong to several families, including Amaryllidaceae, Anacardiaceae, Apiaceae, Apocynaceae, Asclepiadoideae, Asteraceae, Bignoniaceae, Clusiaceae, Chancapiedra, Combretaceae, Cyperaceae, Euphorbiaceae, Fabaceae, Geraniaceae, Lamiaceae, Lauraceae, Lythraceae, Menispermaceae, Myristicaceae, Myrtaceae, Oleaceae, Papaveraceae, Plumbaginaceae, Poaceae, Ranunculaceae, Rosaceae and Theaceae $[3,8,14]$.

The anti-H. pylori activity of plant extracts, infusions or decoctions, as well as essential oils or other plant compounds is studied in vitro usually by way of the disc diffusion method or the micro-dilution method $[1,4,5,7,9,11,15]$. The latter is recommended by the Clinical and Laboratory Standards Institute (CLSI) in USA and the European Committee on Antimicrobial Susceptibility Testing (EUCAST) for determining MIC of antimicrobial substances [18]. As proposed by O'Donnell et al. [10], the bioactivity of the naturally occurring and synthetic substances should be defined as 'moderate' in case of MIC $=126-500 \mathrm{mg} / \mathrm{ml}$, as 'good' in case of MIC $=26-125 \mu \mathrm{g} / \mathrm{ml}$, and as 'strong' with $\mathrm{MIC}=10-25 \mu \mathrm{g} / \mathrm{ml}$. In this paper, the activity in vitro of the plant extracts obtained from species belonging to Asteracea (extracts from coneflower herbs and chamomile flower), and to Lamiaceae (extracts from peppermint leaf and thyme herbs) towards the reference strain H. pylori ATCC 43504 was determined using the micro-dilution broth method. The obtained MIC data indicate that the assayed extracts, especially those obtained with ethyl acetate or ethanol (99.8\%), possessed strong or good in vitro activity against H. pylori ATCC 43504. These results are comparable to that of the representative components of essential oils such as bisabolol, menthol and thymol. Further studies will be performed to confirm the activity of these extracts against clinical $H$. pylori isolates, including those showing drug resistance, and to study a possible mechanism of their anti-H. pylori activity.

\section{CONCLUSION}

The results presented in this paper indicate that coneflower herbs, chamomile flowers, peppermint leaves and thyme herbs cultivated in the Lubelszczyna region can be regarded as potential herbal medicines having promising bioactivity anti-H. pylori, and having potential for being used in prophylaxis or as adjuvant agents in $H$. pylori infection treatment.

\section{REFERENCES}

1. Boyanova L.: Comparative evaluation of the activity of plant infusions against Helicobacter pylori strains by three methods. World J. Microbiol. Biotechnol., 30, 1633, 2014.

2. Dorman H.J.D, Deans S.G.: Antimicrobial agents from plants: antibacterial activity of plants volatile oils. J. Appl. Microbiol., 88, 308, 2000.

3. Edris A.E.: Pharmaceutical and therapeutic potentials of essential oils and their individual volatile constituents: A review. Phytother. Res., 21, 308, 2007.

4. Fadda G., Zanetti S.: In vitro activity of essential oil of Myrtus communis L. against Helicobacter pylori. Int. J. Antimicrob. Agents., 30, 562, 2007.

5. Falsafi T. et al.: Chemical composition and anti-Helicobacter pylori effect of Satureja bachtiarica Bunge essential oil. Phytomedicine., $15,173,2015$.

6. French G.L.: Bactericidal agents in the treatment of MRSA infections - the potential role of daptomycin. J. Antimicrob. Chemother. 58, 1107, 2006.

7. Hazzit M. et al.: Chemical composition and biological activities of Algerian Thymus oils. Food Chem., 116, 714, 2009.

8. Lang G., Buchbauer G.: A review on recent research results (20082010) on essential oils as antimicrobial and antifungals. A review. Flavour Fragr. J., 27, 13, 2012.

9. Njume C. et al.: Volatile compounds in the stem bark of Sclerocarya birrea (Anacardiaceae) possess antimicrobial activity against drugresistant strains of Helicobacter pylori. Int. J. Antimicrob. Agents., 38, 319, 2011.

10. O'Donnell F. et al.: A study of the antimicrobial activity of selected synthetic and naturally occurring quinolines. Int. J. Antimicrob. Agents., 35, 30, 2010.

11. Ohno T. et al.: Antimicrobial activity of essential oils against Helicobacter pylori. Helicobacter, 8, 207, 2003.

12. Papastergiou V., Georgopoulos S.D., Karatapanis S.: Treatment of Helicobacter pylori infection: past, present and future. World J. Gastrointest. Pathophysiol., 5, 392, 2014.

13. Rios J.L., Recio M.C.: Medicinal plants and antimicrobial activity. J. Ethnopharmacol. 100, 80, 2005.

14. Safavi M., Shams-Ardakani M., Foroumadi A.: Medicinal plants in treatment of Helicobacter pylori infections. Pharm. Biol., 28, 1, 2014.

15. Shikov A.N. et al.: Antibacterial activity of Chamomilla recutita oil extract against Helicobacter pylori. Phytoter. Res., 22, 252, 2008.

16. Vale F.F., Oleastro M.: Overview of the phytomedicine approaches against Helicobacter pylori. World J. Gastroenterol., 20, 5594, 2014.

17. Vitor J.M.B., Vale F.F.: Alternative therapies for Helicobacter pylori: Probiotics and phytomedicine. FEMS Immunol. Med. Microbiol., 63, 153, 2011.

18. Wiegand I., Hilpert K., Hancock R.E.W.: Agar and broth dilution methods to determine the minimal inhibitory concentration (MIC) of antimicrobial substances. Nat. Protoc. 3, 163, 2008. 